\title{
Hard Rock Mining Using Disk Tools Supported by High-Pressure Water Jets in the Aspect of Reducing Energy Consumption
}

\author{
Krzysztof Kotwica (D)
}

Citation: Kotwica, K. Hard Rock Mining Using Disk Tools Supported by High-Pressure Water Jets in the Aspect of Reducing Energy Consumption. Energies 2021, 14, 2595. https://doi.org/10.3390/en14092595

Academic Editor: Kamel Hooman

Received: 6 April 2021

Accepted: 28 April 2021

Published: 1 May 2021

Publisher's Note: MDPI stays neutral with regard to jurisdictional claims in published maps and institutional affiliations.

Copyright: (C) 2021 by the author. Licensee MDPI, Basel, Switzerland. This article is an open access article distributed under the terms and conditions of the Creative Commons Attribution (CC BY) license (https:// creativecommons.org/licenses/by/ $4.0 /)$.
Faculty of Mechanical Engineering and Robotics, AGH University of Science and Technology, Mickiewicza Ave. 30, 30-059 Kraków, Poland; kotwica@agh.edu.pl; Tel.: +48-607467-068

\begin{abstract}
The mining of hard rocks by mechanical methods, using cutting tools, is associated with problems such as sparking, dust generation and increased wear. The application of disk tools allows limiting these problems but requires constructing a machine with large dimensions and weight. To limit these problems, high-pressure water jets can be applied. The article presents the effects of using this solution in the field and stand tests when mining rocks with a symmetrical disk. The results of the bench tests of high-pressure water jets to support the process of mining with symmetrical disks, carried out at the AGH University of Science and Technology, performed on a unique test stand, which enabled the samples to be mined in a circular trajectory in conditions similar to real ones, are presented. With the use of a dimensional analysis, a theoretical-empirical model was developed to estimate the impact of slots cut by water jets on the tool load and the amount of output as a function of slots spacing and depth. Considering the similarity criteria for the mined rock sample (mechanical properties), it is possible, with the use of this model, to estimate the most advantageous working parameters while hydromechanical mining uses disks on a larger cutting radius.
\end{abstract}

Keywords: disk tool; hard rock mining; high-pressure water jet assistance; energy consumption

\section{Introduction}

The drilling of underground roadways, especially tunnels, is currently done mainly by mechanical methods, using chiefly roadheaders and TBM (Tunnel Boring Machines). The mining of galleries with the use of cutting tools in hard rock types, i.e., granite, dolomite and sandstone with compressive strength above $100 \mathrm{MPa}$, containing inclusions of abrasive minerals, is associated with big problems due to the rapid wear of these tools, and, in consequence, an increase in their temperature, load and dust, as well as the risk of sparking, which may trigger an explosion of mine gases.

The problem of wear and temperature of the tools, as well as dust and friction spark generation during the mining process, have been minimised by using disk tools [1]. However, to work properly, these tools require pressure force of extremely high values, which affects the dimensions, weight and cost of the mining machine, making its use economically justified only in the case of workings with runouts over several kilometres [1,2].

The wear of cutting tools, especially conical picks, can be reduced by changing the design and material of the picks, especially carbide inserts. The best results, however, can be obtained by using high-pressure water (HPW) jets in the rock mining process. The most effective is individual, internal assistance of the picks located on the mining head [1-4].

In the case of disk tools, the application of HPW jets in the mining process may also increase the mining efficiency or more importantly, significantly reduce the required values of the tool pressure force, and, consequently, the size, weight and cost of the machine while maintaining the same efficiency [5-7]. This may extend the scope of application of TBM machines, which mine using disk tools by the static crushing method. 
Works on the application of HPW jets in the process of rock mining with cutting tools were carried out in many research centres around the world, including in the USA, Great Britain, Germany, Australia, the Czech Republic, Poland and Russia [3,4,8-13]. Investigations were conducted for four different configurations of an HPW jet in relation to the pick edge. A view of these configurations and the scheme of the three most often used solution is shown in Figure 1 [1,14]. Based on the analysis of the test results described in the above publications, it can be concluded that both the location and parameters of HPW jets have a large impact on the obtained effect. The best results were observed in the case of water jets going through the cutting pick edge (Figure 1a). Depending on the value of nozzle diameter and supply pressure, the pick load was reduced from $40 \%$ to $95 \%$, dust was reduced up to $90 \%$ and pick edge wear was reduced up to $90 \%$, with complete elimination of friction spark. However, such an arrangement of the jet is only possible under laboratory conditions. In practice, the nozzle in the pick edge gets damaged quickly [13-15].
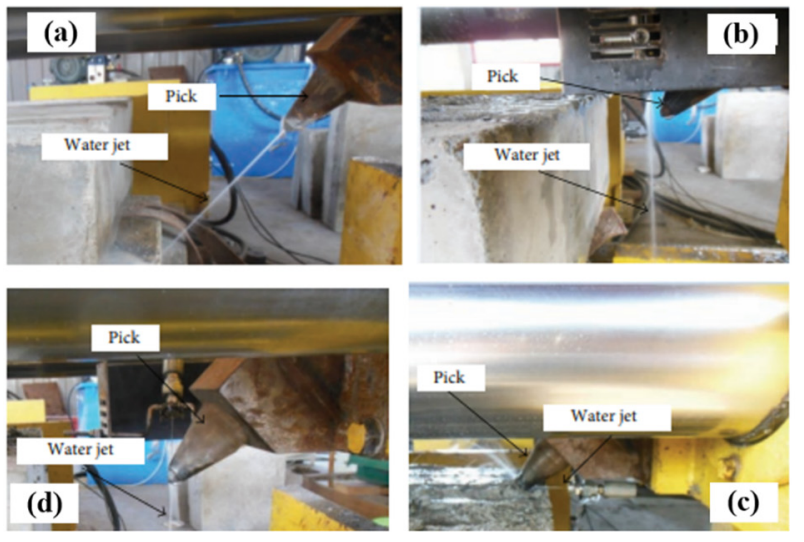

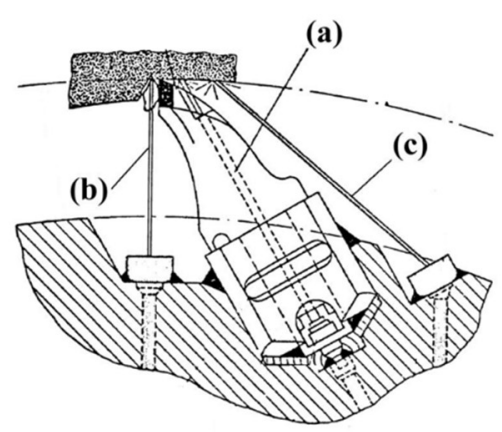

Figure 1. View and scheme of configurations of the high-pressure jet in relation to the cutting pick edge: (a) inside, in the pick axis, (b) in front of the pick edge, (c) behind the pick edge, (d) on the side of the pick edge [14].

In order to reduce the load on the cutting tool in industrial conditions, it is best to place the water jet along the axis of the tool, in front of its edge (Figure 1b). Depending on the cutting parameters, the value of the nozzle diameter and the supply pressure, a 10-40\% reduction of the load on the tool can be achieved [1-4,16].

When the water jet is located behind the pick (Figure 1c), it is possible to reduce the load on the tool by up to $12-15 \%$. In the case of this arrangement of the nozzle, increased diameter or supply pressure do not have a significant impact on load reduction. However, the generation of friction spark was eliminated, and the level of dust drastically reduced, by as much as $90-95 \%[1,2,17,18]$.

The least favourable position of the nozzle was that on the side of the pick edge (Figure 1d). In this case, the reduction of the load on the tool is almost imperceptible. Additionally, the level of dust is only slightly reduced. The location of the high-pressure jet does not have a big impact on the wear of cutting tool edges, although it is preferable to place the nozzle in front of the pick.

The use of HPW jets in the mining of rocks with cutting tools reduces the dust hazard and the risk of methane ignition due to friction sparks, but it does not always prevent uneven wear of conical picks. This results chiefly from the irregular, random rotation of picks in their handles or the absence of the latter, which is mainly caused by high resistance to their rotation due to contamination of the handles and the increased friction coefficient. In practice, this applies to approximately $60 \%$ of picks $[1,17]$. Therefore, the application of the cutting method for mining hard rocks is in practice economically unjustified.

Much better results can be obtained by using disk tools, which mine the rock in the process of static crushing. To reduce the inconvenience associated with high-pressure forces and dimensions as well as the weight of TBM, it is also possible to apply HPW jets to support the mining process [1,19-21]. 
The impact of pressure force on the required machine weight is shown in Figure 2. A reduction in the TBM's mass by approximately $50 \%$ can be achieved by reducing the value of the required pressure force by approximately $30 \%[5,6]$, whereas reducing the mass and dimensions of the machine by about $20 \%$ makes its use profitable for drilling tunnels with runouts stretching over 1 to $2 \mathrm{~km}$. Thus, the share of TBM miners for excavating workings with a circular cross-section could be increased in the total number of mechanically drilled workings by more than two-fold [6].

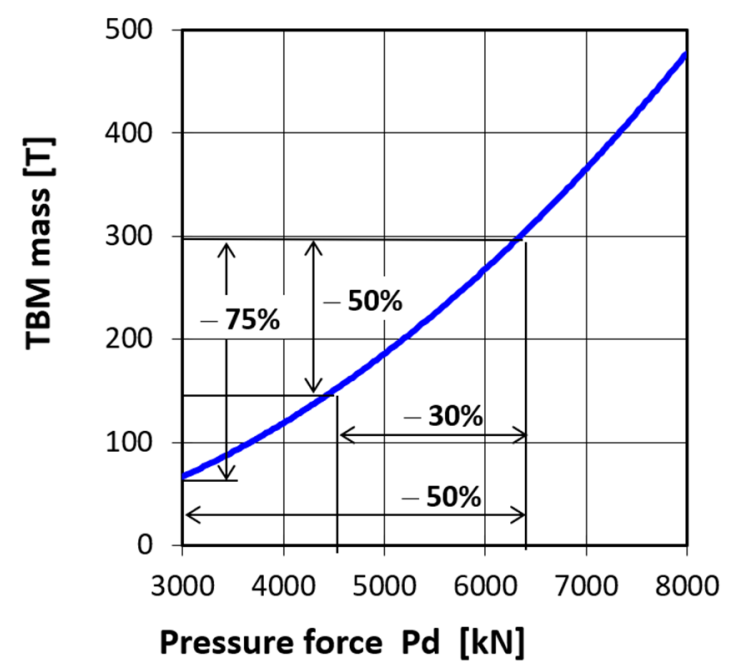

Figure 2. Influence of the TBM's pressure force on its mass [6].

Research on the use of HPW jets supporting the process of mechanical mining with disk tools was conducted mainly in Russia, Germany, the United States and China. The investigations in Russia, at the Mining Institute Skoczyński in Lubierce near Moscow [11,12], were conducted in laboratory conditions on symmetrical and asymmetrical smooth disk tools with an edge angle $\beta$ of 300 and diameter $D$ of $200 \mathrm{~mm}$. Artificial carbon-cement blocks were mined along a straight line, i.e., in a manner similar to that of disk tools on the longwall shearer mining head. The process of sample mining was supported by water jets with pressure $p$ of up to $35 \mathrm{MPa}$ and nozzle diameter $d$ of up to $2.0 \mathrm{~mm}$. The nozzles were arranged in the axis of the disk tool and symmetrically on its sides, or only on one side and symmetrically on the tool's sides (Figure 3). The impact of using high-pressure jets on the value of forces acting on the disk tool, energy consumption and mining effect, the amount of dust and output grain fraction $+25 \mathrm{~mm}$ were measured.
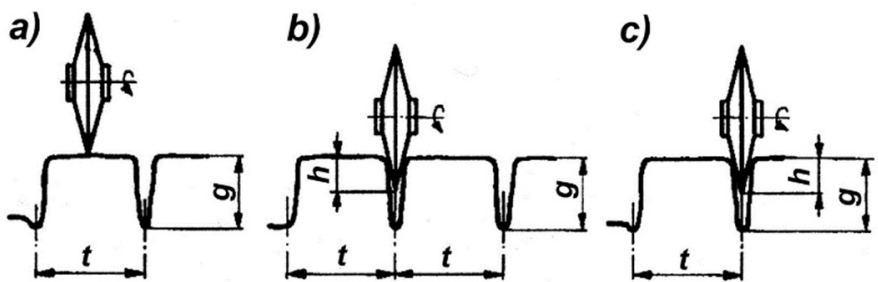

Figure 3. Diagram of the arrangement of slots cut with high-pressure jets in relation to the disk tool, (a) on the sides of the tool, (b) on the sides and along the axis of the tool and (c) on one side and along the axis of the tool [11,12].

The best results were achieved after cutting three slots: one slot along the axis of the disk tool and two slots symmetrically on the tool sides, as shown in the diagram in Figure $3 \mathrm{~b}$. When two slots were cut, one was along the axis of the tool and the other on the side - see Figure 3c-using an asymmetrical disk tool [11,12]. A significant reduction in the required value of pressure force $P d$, up to 1.4 times, side force $P b$, up to 4.4 times, and tangential force $P_{s}$, up to 2.0 times, was obtained. The yield output grain fraction $+25 \mathrm{~mm}$ 
increased to $85 \%$ of the total output and the level of dustiness dropped by $99.8 \%$. However, this involved cutting an additional slot along the trajectory of the disk tool movement and increasing the total unit mining energy $E_{j c}$ by $1.9 \div 2.2$ times, especially in the case of mining with three slots. Such good results, in particular dust reduction and an increase in the output grain fraction $+25 \mathrm{~mm}$, were achieved owing to the fact that the disk tool edge acted like a wedge while penetrating into the cut slot and cutting the rock sides between the slots [11,12].

Works on supporting the process of hard rock mining with disk tools by using HPW jets began on an industrial scale in the early 1970s, mainly in the United States and Germany. HPW jets were used to support the mining of very hard rocks by means of TBM for excavating workings with a circular cross-section [5-7].

The research conducted in the USA was supervised by the US Bureau of Mines and the National Science Foundation. It was carried out in 1974 in real conditions when drilling a tunnel in granite rocks with a uniaxial compressive strength $R_{c}$ of more than $220 \mathrm{MPa}$, in a quarry in the state of Washington. A Robbins TBM with a diameter of $2.1 \mathrm{~m}$ was used for drilling $[7,22]$. The drilling head was equipped with 21 symmetrical single smooth disk tools with a diameter of $365 \mathrm{~mm}$, which were supported by water jets with a pressure of up to $414 \mathrm{MPa}$ from 31 nozzles with a diameter of $0.2,0.3$ or $0.4 \mathrm{~mm}[7,20]$. Water jets cut the slots symmetrically on the sides of the mining disk tool. The head pressure force against the face reached up to $1700 \mathrm{kN}$. The main goal of the research was to determine the impact of HPW jets on the mining speed and the costs of mining a roadway. During the experiments, the spacing of the nozzles was changed and their diameter was selected in such a way that the cut slots maximally facilitated the work of disk tools [10]. During the tests, a 50\% increase in the mining speed was obtained compared to mining without water jet support. Graphs of the advance speed in the process of mining with and without HPW jet assistance as a function of head pressure force against the face have been presented in Figure 4, whereas Figure 5 shows the effect of increasing the mining speed on the costs of excavating 1 running meter of the heading. Economic calculations have demonstrated that increasing the mining speed by more than $10 \%$ is sufficient to compensate for the additional costs incurred for the HPW jet system and additional energy expenditure to produce high-pressure jets, whereas a $50 \%$ increase in the mining speed allowed reducing the cost of roadway excavation by more than $25 \%$ [7].

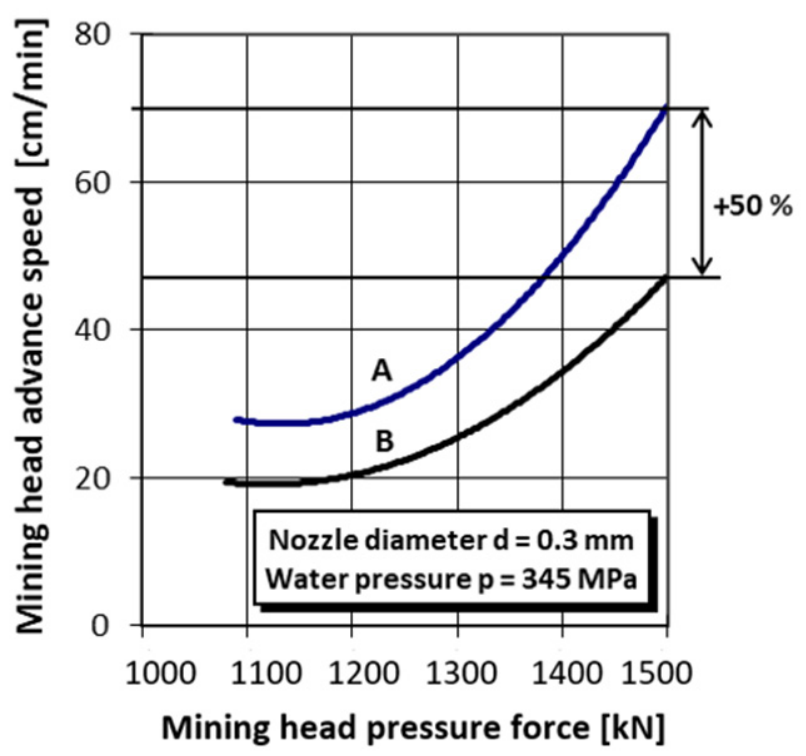

Figure 4. Influence of pressure force on the speed of mining head advance: A-with HPW assistance, B-without HPW assistance [7]. 


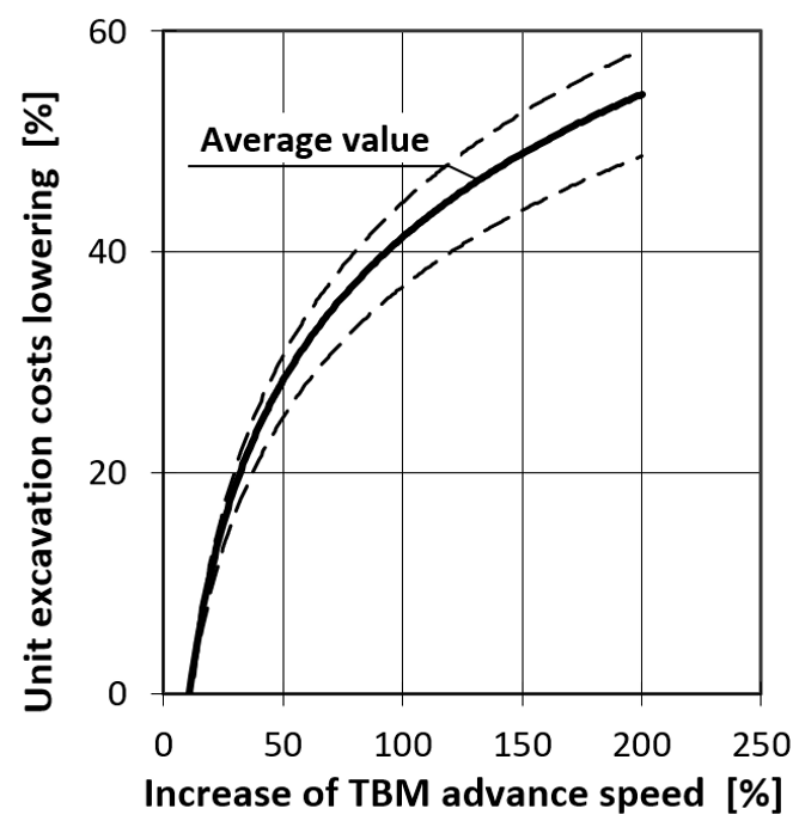

Figure 5. Influence of increasing the speed of mining head advance on the unit costs of roadway excavation [7].

A much more extensive study was conducted in Germany at Bergbau-Forschung $\mathrm{GmbH}$, in collaboration with Wirth and the US Bureau of Mines and Flow Industries, Inc. Seattle, USA. These tests were also carried out in real conditions, in sandstone quarries near Dortmund-Hohensyburg, on a Wirth TBM, model TB-I-260, with a diameter of $2.6 \mathrm{~m}$ (Figure 6) [5-7].

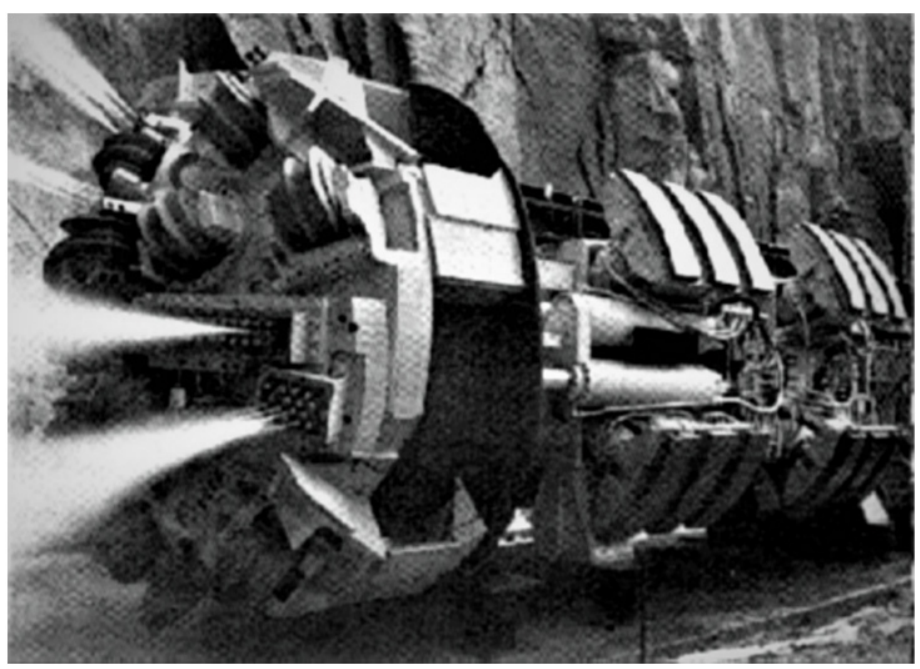

Figure 6. View of a Wirth TBM, model TB-I-260, with HPW jet assistance [7].

The aim of the research was to determine the impact of applying HPW jets on the reduction of the head pressure force against the face. The influence of HPW jet assistance on the mining speed was also subjected to investigations. During the three-year research, tests were conducted with many variable mining parameters $[7,23]$.

Like in the research conducted in the USA, the nozzles were arranged on the sides, symmetrically to the axis of symmetrical disk tools, according to the diagram shown in Figure $7[7,17]$. Only the external disk tools in the calibration area were supported by water jets cutting the slots along the tool axis. Up to 70 nozzles [6] were used simultaneously on the head, the pressure of the water jets reaching up to $400 \mathrm{MPa}$. The pressure force 
was reduced by $57 \%$ (Figure $8 \mathrm{a}$ ) as compared to the unassisted mining process (Figure 8a), and the mining speed increased by nearly $100 \%$ (Figure $8 b$ ). As the pressure of water jets supporting the mining process increased, the measured level of dust dropped by $97 \%$ compared to that occurring during mechanical mining [5].

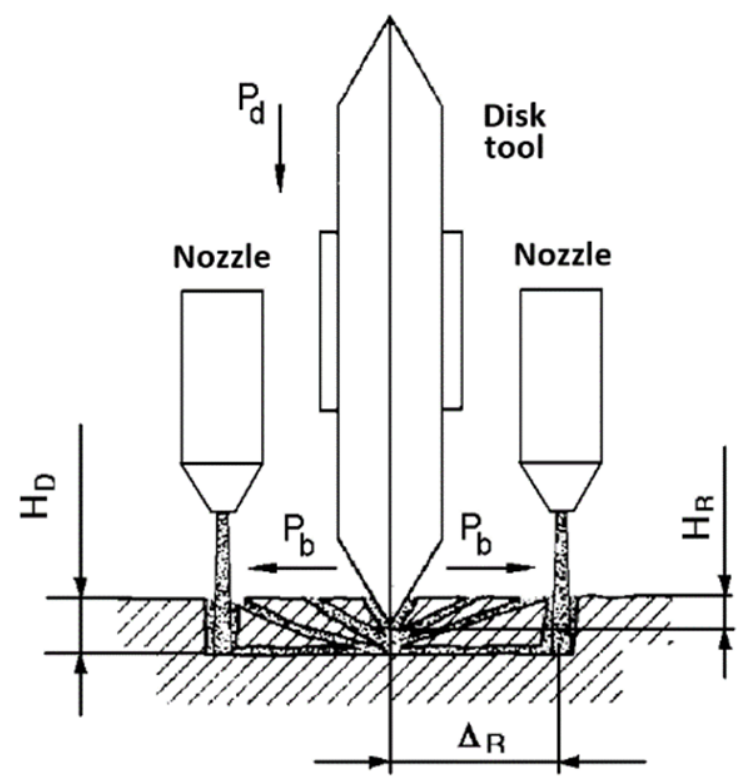

Figure 7. Diagram of mining with a disk tool assisted by HPW jets, applied on a Wirth TBM, model TB-I-260 [7,23]. $\mathrm{H}_{\mathrm{R}}$ - disk penetration depth, $\mathrm{H}_{\mathrm{D}}$-depth of slots cut with water jets, $\Delta_{\mathrm{R}}$-distance of the nozzle axis from the plane defined by the edge of the mining disk.

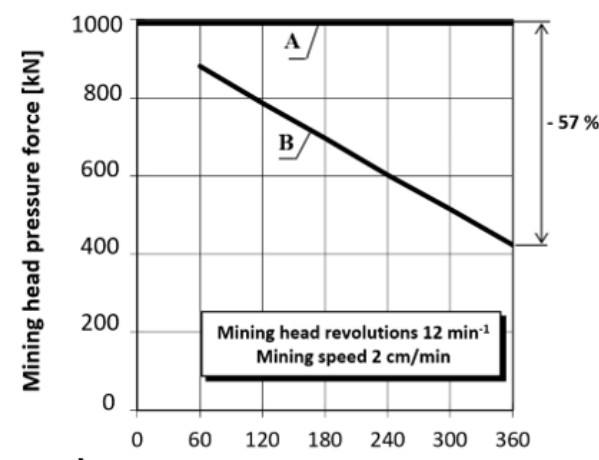

a)

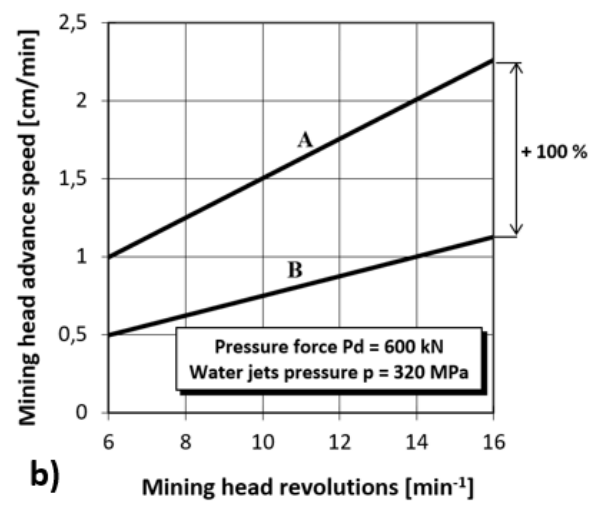

b)

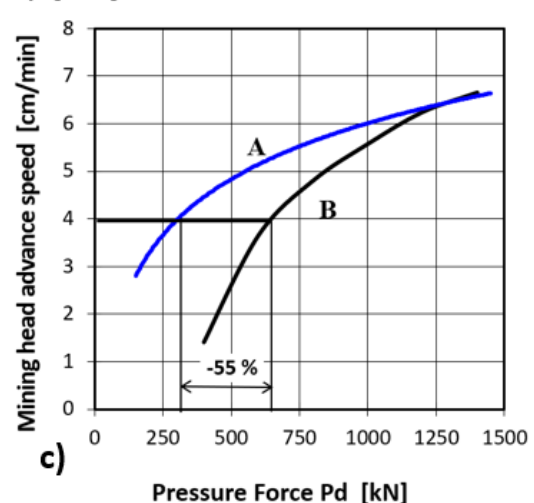

Figure 8. Influence of: (a) the pressure of water jets supporting the mining process on the value of the head pressure force: (b) the number of head revolutions on the machine advance speed, (c) the value of the pressure force on the machine advance speed [6]; A—without HPW assistance, B—with HPW assistance. 
The variability of forces acting on individual disk tools was also measured. The maximum force values for mining disk tools without HPW jet assistance reached $330 \mathrm{kN}$. With the assistance, the force values did not exceed $220 \mathrm{kN}$. High variability of forces caused a ca. $40 \%$ increase of the wear of disk tools used in the unassisted mining process, especially in the calibrating area [6].

Based on the test results, the influence of pressure force on the speed of mining in the case of the assisted and unassisted mining process was determined (Figure 8c) [6,7]. As can be seen, the increased speed of head advance causes a decrease in the positive effect of HPW jets, which finally disappears completely.

Researchers at the Tianjin University in China conducted similar research on the application of HPW jets when excavating a tunnel with a TBM miner in very hard granitetype rocks. The influence of the arrangement of water nozzles as well as the parameters of the water jet and of disk tool mining on the mining efficiency and disk tool load was investigated [21]. The nozzles were positioned along the axis of the 17-inch diameter disk or on its sides at a distance of $81 \mathrm{~mm}$, and the slots were cut to a depth of 2,4 and $6 \mathrm{~mm}$. The slots were cut prior to the disk mining process. The view and diagram of the slots cut during the tests are shown in Figure 9. When mining with a disk to a depth of $4 \mathrm{~mm}$, the value of pressure force $\mathrm{Pd}$ was significantly reduced. The reduction was greater for two slots cut on the sides of the disk and for the maximum slot depths of $6 \mathrm{~mm}$. The amount of mined rock also increased for this configuration of nozzles. It has been presented in the graphs in Figure 10. The results obtained during the research were used to develop and manufacture the first TBM miner on the Chinese market, which was equipped with HPW jet assistance [21].
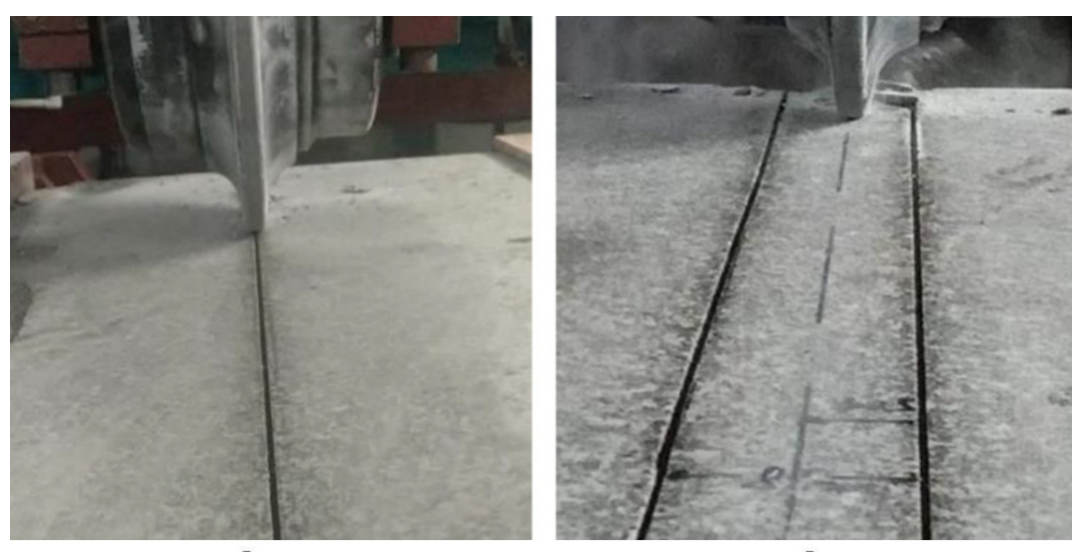

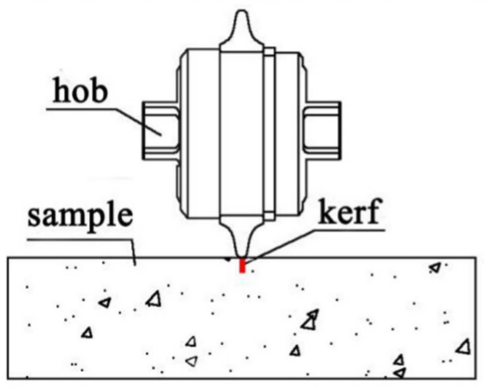

(a)

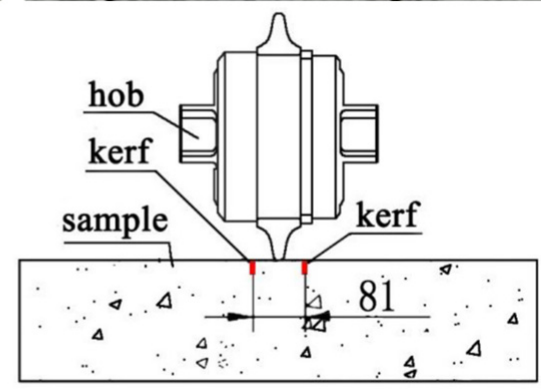

(b)

Figure 9. View and diagram of slots cut in relation to the disk tool during the mining tests at the laboratory stand: (a) slot along the disk axis, (b) two slots on the sides of the disk [21]. 


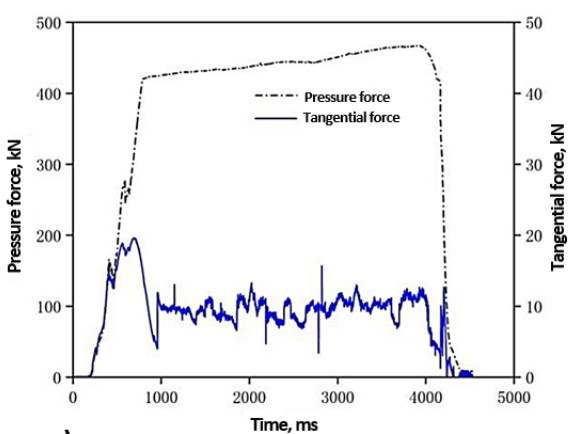

a)

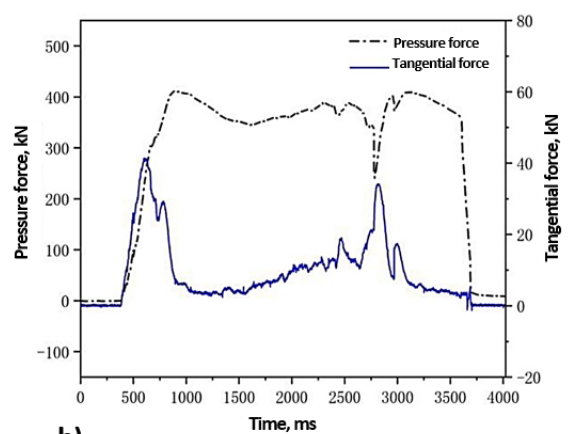

b)

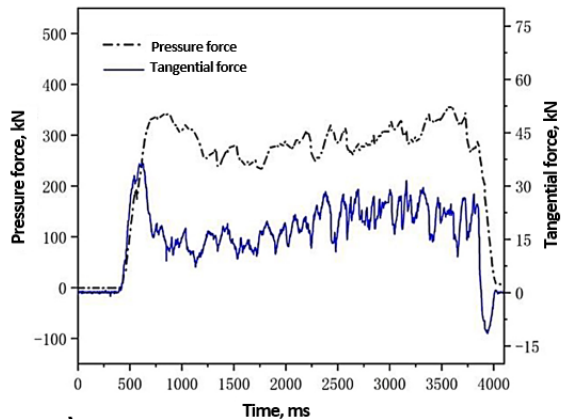

c)

Figure 10. Results of applying HPW jets in the process of mining with a disk tool: the value of pressure force Pd; (a)—without HPW, (b)—with HPW—slots distance $81 \mathrm{~mm}$, slots depth $4 \mathrm{~mm}$, (c)—with HPW—slots distance $81 \mathrm{~mm}$, slots depth $6 \mathrm{~mm}$, (according to [21]).

\section{Purpose, Scope and Methodology of the Research Activities}

The above-described effects of applying HPW jets to support the mining process allow concluding that the influence of HPW jets on disk tool load and on the amount of mined rock is significant. These results were obtained in tests or field trials, during which it was not possible to thoroughly verify the influence of individual parameters of the mining process and high-pressure jets on the final result. At the University of Xuzhou in China, the mechanism of rock destruction was analysed in the process of disk tool mining supported by HPW jets. Using the finite element method (FEM) and the smoothed particle hydrodynamics (SPH) method, a numerical model of mining the rock with a disk tool and an HPW jet was developed [24]. Based on the numerical model, the influence of individual parameters of the mining process on its efficiency was investigated. The selected results were verified during an experiment of cutting marble with a water jet. An HPW jet can increase the TBM mining capacity and reduce the load and wear rate of the disk tool. According to the obtained results, the optimal diameter of the nozzle was $1.5 \mathrm{~mm}$, and the jet velocity was $224.5 \mathrm{~m} / \mathrm{s}$ for the simulation [24]. However, both in the case of the results obtained empirically and during simulation tests, the number of investigated parameters was limited and they were changed to a small extent. Only general correlations between the depth of the cut slots and their spacing in relation to the disk tool and the reduction of the pressure force and energy consumption of the mining process were determined.

The author conducted extensive research on the method of hydro-mechanical mining of rocks with the use of static disks at the Department of Mining, Processing and Transport Machines at the AGH University of Science and Technology in Cracow [1]. An important issue was to determine the influence of HPW jet assistance (the depth of the cut slots and their spacing in relation to the axis of the disk tool) in the process of mining with a single disk tool on its load as well as on the efficiency and energy consumption of the mining process. The tests were performed on a unique test stand, enabling the samples to be mined in a circular trajectory, in conditions similar to real ones, as on a TBM. Other test stands usually allowed the mining of the rock sample in a straight line.

The course and results of laboratory tests have been presented below. They allow determining the impact of HPW jets on the process of rock mining with symmetrical disk tools as well as comparing the obtained results with mechanical mining. On their basis, the author developed a theoretical-empirical model of hydromechanical mining of rocks with symmetrical disk tools. With the use of similarity criteria, this model can be used in a wider area when mining rocks with different physic-mechanical properties or mining parameters other than during the tests.

The tests were carried out on a stand for testing single mining tools [1]. It consists of a frame on which the traverse moves vertically. The traverse is equipped with a sliding mounted support with a mining tool holder, which can move horizontally along the traverse. Concrete samples modelling the rock were placed on a turntable, which gave them a rotary motion. The table was driven by the SH-1 main rotational hydraulic motor 
and the main gear; the vertical movement of the traverse was executed by the SH-2 advance hydraulic motor, while the horizontal movement of the support towards the sample axis was executed by the stroke of a hydraulic cylinder $\mathrm{CH}$. Flat concrete samples with a diameter of $1200 \mathrm{~mm}$ and a height of $160 \mathrm{~mm}$ were mounted on the rotary table, whereas the disk tool holder was attached to the support plate. This enabled mounting and testing disk tools with a diameter of $400 \mathrm{~mm}$ as well as frontal mining of a concrete sample with a maximum pressure force $P d$ of up to $250 \mathrm{kN}$, with an adjustable number of sample revolutions from 0 to $251 / \mathrm{min}$. The mining radius could be freely changed from 0 to $550 \mathrm{~mm}$. This corresponded to the mining parameters applied in TBM miners when mining the central part of the face. The diagram and view of this laboratory stand for investigating the mining process with symmetrical disk tools assisted by HPW jets is shown in Figure 11 [1]. It was assumed that HPW jets would symmetrically cut slots in the rock mass on the sides of the disk tool according to the diagram in Figure 12.

a)

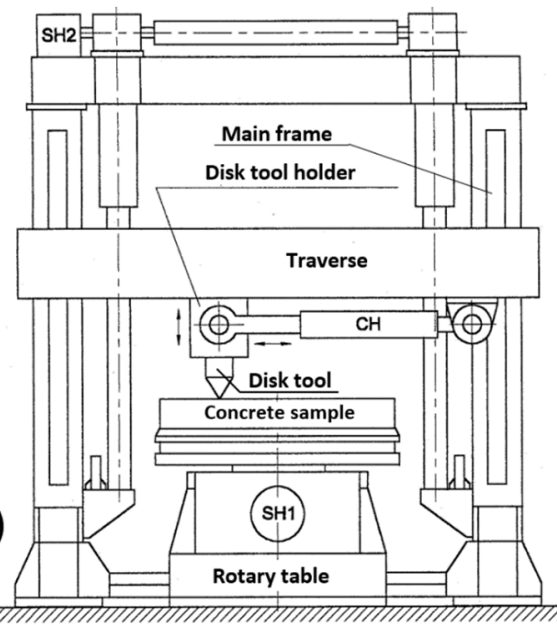

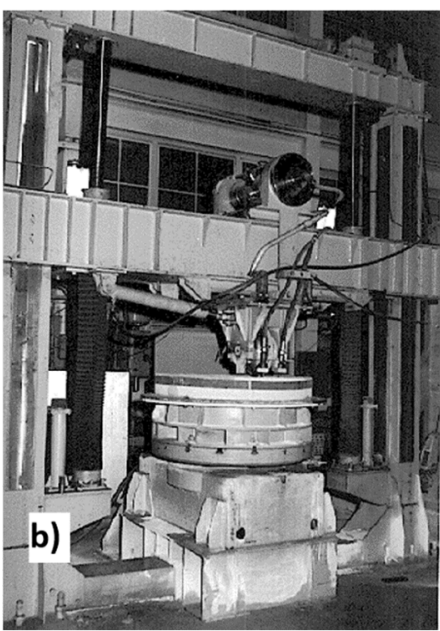

Figure 11. The test stand for testing single tools, preparing to mine the concrete sample with a disk tool with high pressure water jet assistance: (a) the scheme, (b) photo [1].

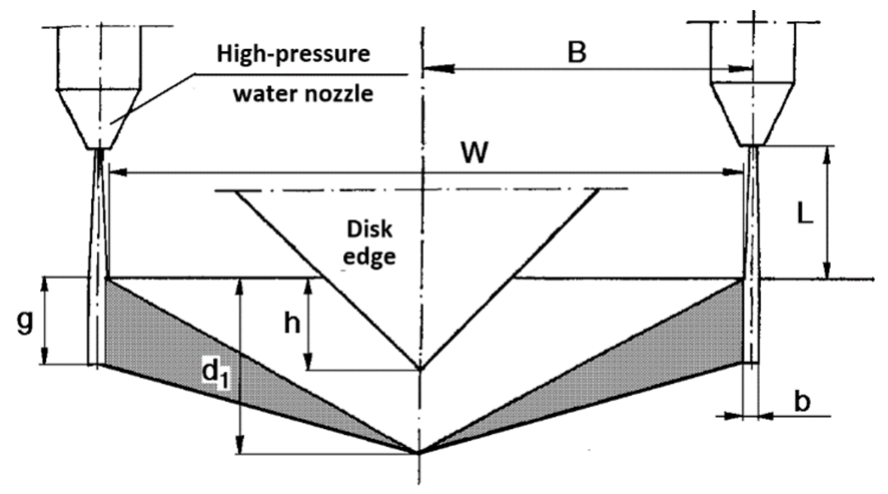

Figure 12. The diagram of mining by means of a symmetrical disk tool with assistance of HPW jets located on the sides of the disk tool [1].

The high-pressure jets made two slots in advance at depth $g$ and width $b$ on the cut border, at distance $B$, comparable to half of the predicted theoretical width of the cut $W$ [1]. The depth of the slots cut by HPW jets was comparable to or greater than the penetration depth of the disk tool edge $h$, which allowed obtaining the cross-section of the cut according to the diagram shown in Figure 13, where:

- $W_{h}$-width of the cut obtained with an HPW jet,

- $h_{z}, h_{w}$-depth of the cut on the outer and inner borders, respectively, next to the cut slots, in mm. 


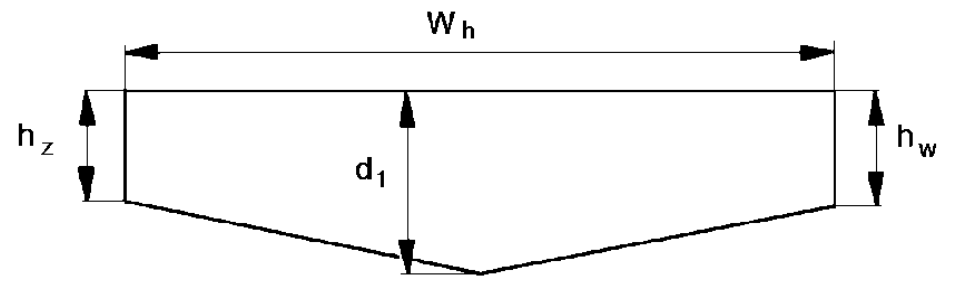

Figure 13. The diagram of a cross-section of the cut obtained by mining with a symmetrical disk tool assisted by two HPW jets located on the sides of the disk tool [1].

However, in this method, strongly changeable side forces on disk tools edges occur. They cause difficulties with a proper transfer of reactions on disk tools chucks and their bearing. An explanation of the phenomenon is presented in Figure 5. In the picture, on the left side, the rock is not chipped off yet, the disk cuts into the rock body, and on the right side, the rock piece is already chipped off. The disk cuts a new mining path in the rock and it is initially pushed away from the working face [17].

In order to determine the working parameters, the load on the disk tool and the mining effects, the following values were measured at the laboratory stand during the tests:

- Load on the symmetrical disk tool: pressure force $P d$, side force $P b$ and tangential force $P S$,

- Pressure of water supplying the nozzles $p$,

- Disc tool edge penetration depth $h$,

- Angular velocity of the probe $\omega$,

- Depth and width of the slot cut with a water jet, $g$ and $b$

- Effect of mining with a disc tool, $W, W_{h}, d_{1}, \mathrm{~h}_{\mathrm{z}}$ and $\mathrm{h}_{\mathrm{w}}$, according to the diagrams in Figures 12 and 13.

First of all, the influence of the value of the spacing $2 \mathrm{~B}$ and the depth of the cut slots $\mathrm{g}$ on the value of the $\mathrm{Pd}, \mathrm{Ps}$ and $\mathrm{Pb}$ forces acting on the disk tool and the parameters of the obtained cut, as a function of three different angles of the disk tool wedge $2 \beta$ and three different cutting radius $\mathrm{Ru}$, was measured. The parameters of the nozzle supply (water pressure $p$ ) and the diameter of the nozzle $d$ made it possible to make slots to a depth $g$ of 7.5 to $15 \mathrm{~mm}$, and the spacing of the slots $2 \mathrm{~B}$, depending on the angle of the tool wedge, ranged from 50 to $120 \mathrm{~mm}$. This range of used and measured parameters allowed for obtaining sufficient information on the impact on the change in the values of the above-described quantities. This is described in more detail later in the article.

The load on the disk tool was measured with a set of strain gauges embedded in the holder along the tool axis. The measuring system calibration enabled direct measurement of pressure force $P d$, tangential force $P s$ and side force $P b$. The water jet pressure was measured with an AR-008 pressure sensor, the disk tool edge penetration depth was measured with a PLT250 inductive displacement sensor, while the value of the table rotational speed was measured with a magnetic pulse counter. All the above-mentioned values were measured, recorded on a measuring computer and, next, processed.

The mining effect, i.e., depth $g$ and width $b$ of the slot cut by a water jet, as well as depth $d_{1}$ and width $W$ and $W_{h}$ of the cut obtained by mining the surface of the concrete sample with a disk tool, were measured with an accuracy of $0.1 \mathrm{~mm}$ using a special instrument based on a calliper and depth gauge. The depth of the outer and inner borders $h_{z}, h_{w}$ of the cut made next to the slots during hydro-mechanical mining with a disc tool was measured in a similar way.

During the tests, three types of concrete samples with a uniaxial compressive strength $R_{c}$ of approximately 14.5, 19.5 and 33.0 MPa were cut. During the tests, three types of concrete samples with a uniaxial compressive strength Rc of approximately 14.5, 19.5 and $33.0 \mathrm{MPa}$, simulating hard rock sample, were mined. In one paper [25], it was found that a homogeneous concrete sample is much more difficult to mining (has a higher mining resistance) than, for example, a natural sandstone sample with a compressive strength 
twice as high. Moreover, the concrete samples ensured the repeatability of the physical and mechanical parameters of the mining process. Symmetrical disc tools equipped with a removable single or double smooth blade with a mining diameter $D$ of $400 \mathrm{~mm}$, a width of $60 \mathrm{~mm}$ and a disc edge height of $35 \mathrm{~mm}$ were used in tests. The cutting edge angles were $2 \beta=90^{\circ}, 110^{\circ}$ and $130^{\circ}$. The work of the tools was supported by high-pressure jets from two nozzles mounted in tilt-and-slide sockets, enabling the change of assistance parameters. Saphintec 6300 nozzles with a diameter $d$ of $0.35,0.55$ and $0.8 \mathrm{~mm}$ were used for tests. The nozzles were driven by a hydraulic unit, which allowed obtaining a pressure $p$ of up to $80 \mathrm{MPa}$, with a water discharge $Q$ of up to $601 / \mathrm{min}$ [1].

\section{Results of Mining Tests with a Disk Tool without and with HPW Jet Assistance}

The tests were carried out separately for each mining method: HPW jet, circular symmetrical disk tool without and with high-pressure assistance of two water jets, symmetrically arranged in relation to the disk tool axis. Measurement of the efficiency of mining with an HPW jet enabled determining the parameters of the jets cutting the slots on the sides of the disk tool in order to obtain the desired depth of the slots, comparable to the penetration depth of the disk edge. One of the tests with an HPW jet is shown in Figure 14.

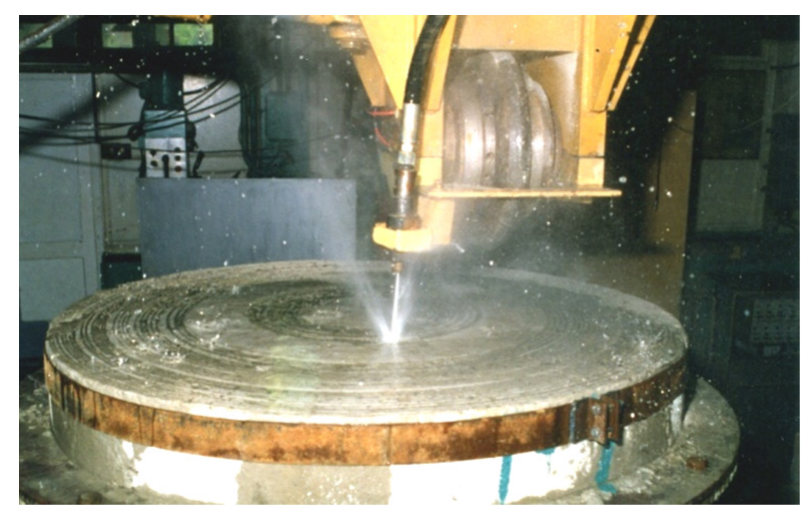

Figure 14. The view of concrete sample cutting using HPW jet: $\mathrm{d}=0.8 \mathrm{~mm}, \mathrm{~L}=70 \mathrm{~mm}, p=60 \mathrm{MPa}$ [1].

The tests of mining the samples with a disc tool were conducted separately for mining without and with HPW jets, for three mining radius $R_{u}$ of 250, 350 and $500 \mathrm{~mm}$. Measurements were made using tools with three different edge angles $2 b$ and for samples with three different values of compressive strength $R_{\mathcal{c}}$. In the case of mining without water jet assistance, one cut on the concrete sample was made with a radius $R_{u}$ of $350 \mathrm{~mm}$ and two cuts with radius $R_{u}=250$ and $500 \mathrm{~mm}$, due to the possibility of adjacent cuts interacting with each other.

During the process of mining assisted by an HPW jet, the first slots of a given depth $g$ were made in relation to the disc tool axis on one half of the circumference of the sample with radius $R_{u}$, and next, at a different depth on the other half of the circumference. The slots depth, g, ranged from 7.5 to $15.0 \mathrm{~mm}$, whereas their spacing $2 B$ was within the range of $0.75-1.75$ of the theoretically calculated width of the cut $W$, according to the theory of disc tool edge penetration presented by Dutta and Marianowski [26,27].

The mining trials for each sample were performed for three cutting radius $R_{u}$. Several mining tests were also performed when only one half of the concrete sample had slots cut with high-pressure jets. The working cycle of the rock sample mining process with the use of a disk tool was divided into two phases: vertical penetration of the disk tool edge at the selected depth $h$ and turning the disk tool along a circle with a given depth, at a rotational speed of the table $\omega=111 / \mathrm{min}$, comparable to the rotational speed of TBM miner heads.

The view of the stand during the tests of mining concrete samples with a disk tool without and with HPW jets is shown in Figure 15, whereas the view of one of the cuts obtained in the process of mining without and with water jet assistance, with a cutting radius $R_{u}$ of $250 \mathrm{~mm}$ has been presented in Figure 16. 

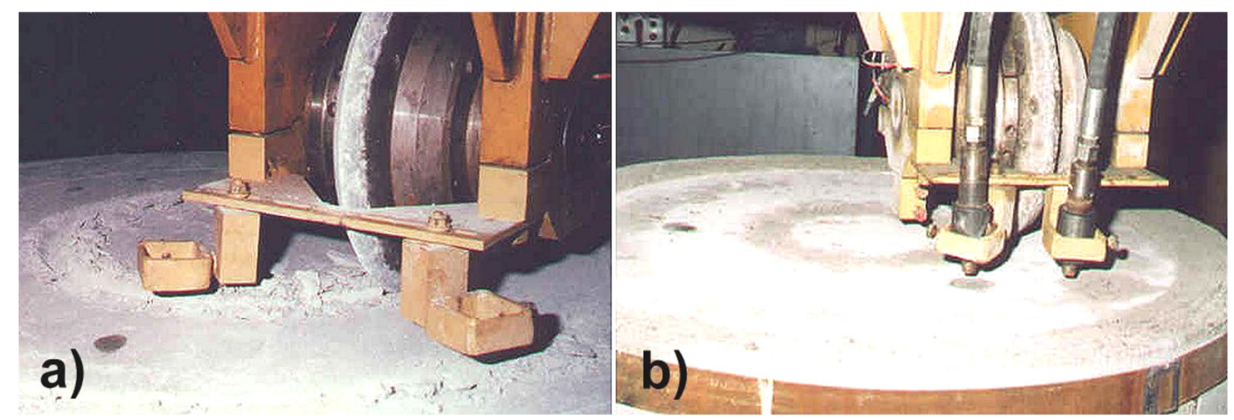

Figure 15. View of the test stand for testing single tools: (a) during concrete sample mining using a symmetrical disk tool, (b) ready to test with a disk tool assisted by high pressure water jets [1].
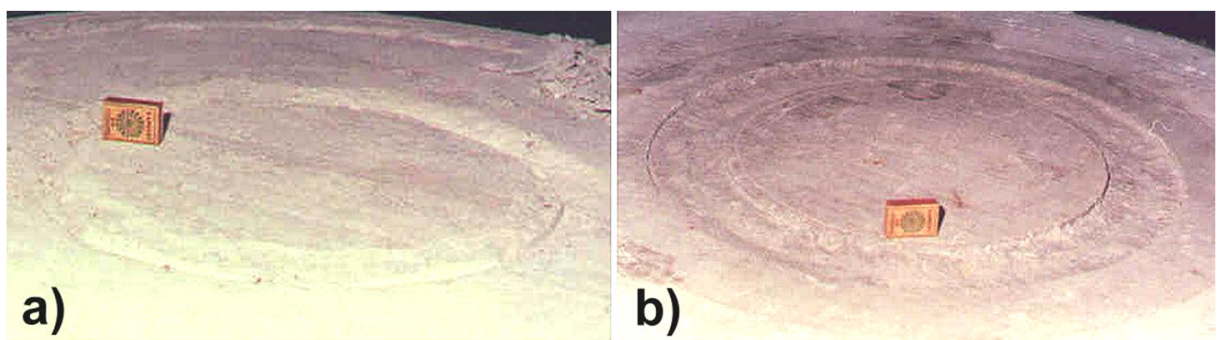

b)

Figure 16. View of the sample surface after mining with a symmetrical disk tool—disk edge angle $2 \beta=110^{\circ}$, mining radius $R_{u}=350 \mathrm{~mm}$ : (a) without high pressure water jet assistance, $(\mathbf{b})$ with high pressure water jet assistance-slots depth $\mathrm{g}=10 \mathrm{~mm}$, slots spacing $2 \mathrm{~B}=70 \mathrm{~mm}$ [1].

The test results were processed in the Microsoft Excel package, which enabled presenting the measured courses for selected mining parameters in the graphic form, conducting their statistical analysis and summarising the average values. The average values of forces acting on the disk tool were calculated for the steady-state operation, after rejecting the initial and final parts of the measurement series. Figure 17 shows an example of the course of the values of pressure force $P d$, tangential force $P s$ and side force $P b$ for the cut which was made without HPW jets on one half of the circumference, and with the HPW jet assistance on the other half. Figure 18 shows the course of the same values when the sample was cut with an HPW jet at two different depths of the cut slots $g$, on each half of the circumference of the cut.

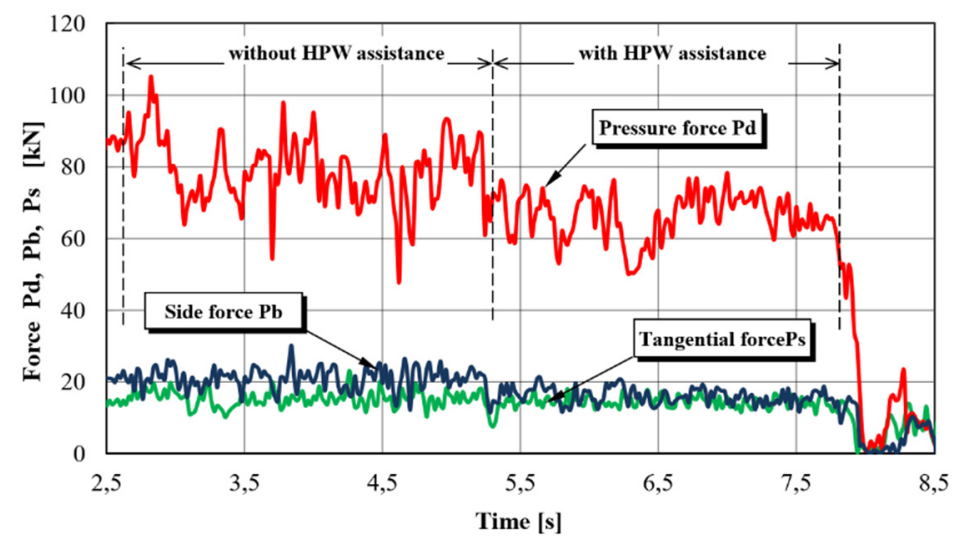

Figure 17. View of the exemplary course of $\mathrm{Pd}, \mathrm{Pb}$ and $\mathrm{Ps}$ force values during mining with disk tool with and without high pressure water jet assistance-concrete sample compressive strength $\mathrm{R}_{\mathrm{c}}=19.5 \mathrm{MPa}$, disk edge angle $2 \beta=90^{\circ}$, mining radius $R_{u}=250 \mathrm{~mm}$, disk edge penetration depth $\mathrm{h}=12.35 \mathrm{~mm}$, slots depth $\mathrm{g}=12.65 \mathrm{~mm}$, slots spacing $2 \mathrm{~B}=80 \mathrm{~mm}$ [1]. 


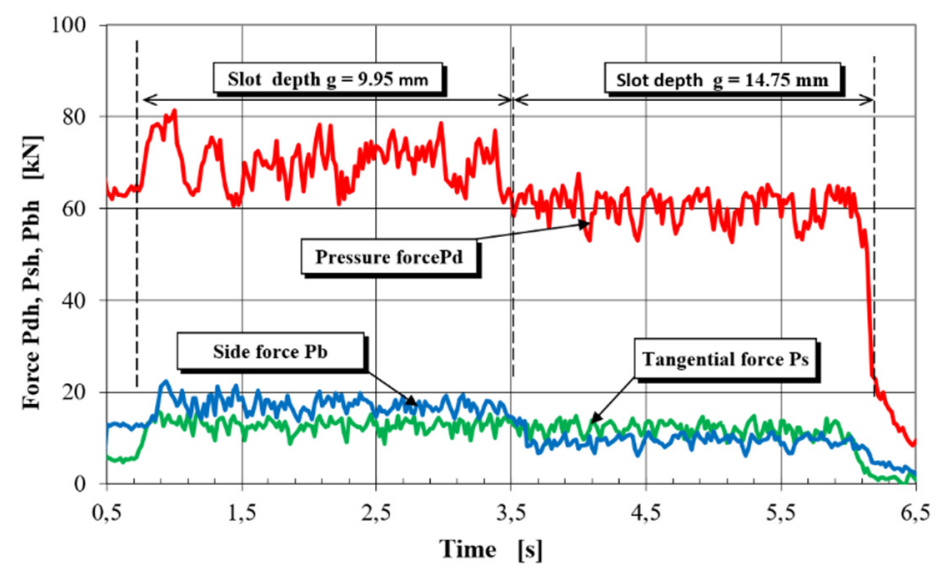

Figure 18. View of the exemplary course of $\mathrm{Pd}, \mathrm{Pb}$ and $\mathrm{Ps}$ force values during mining with disk tool with high pressure water jet assistance-concrete sample compressive strength $R_{c}=19.5 \mathrm{MPa}$, disk edge angle $2 \beta=110^{\circ}$, mining radius $250 \mathrm{~mm}$, disk edge penetration depth $\mathrm{h}=10.15 \mathrm{~mm}$, slots spacing $2 \mathrm{~B}=75 \mathrm{~mm}[1]$.

It can be seen that the values, especially of pressure force $P d$ and side force $P b$, decreased in the case of mining assisted by HPW jets compared to the unassisted mining process. Increasing the depth of slots $g$ also has a strong influence on the drop in the values of pressure force $P d$ and side force $P b$. Apart from the reduction of the mean value of pressure force $P d$ and side force $\mathrm{Pb}$ by approximately $20 \%$ and $28 \%$, respectively, compared to the unassisted mining process, the coefficient of variation $Z_{\mathrm{m}}$ was also reduced for pressure force $P d$ by approximately $25 \%$ and for side force $P b$ by approximately $32 \%$ [1].

The summary of the results for each measurement made during the process of unassisted mining includes the measured depth $\mathrm{d}_{1}$ and width $W_{m}$ of the obtained cut, the calculated volume of output $V_{m}$ obtained with one rotation of the sample, and the unit energy of mining $E_{j m}$. The summary of the results for each measurement made during mining assisted by HPW jets contains the measured depth $\mathrm{d}_{1}$ and width $W_{h}$ of the obtained cut, the chipping depth on the cut borders $h_{w}$ and $h_{z}$ as well as the calculated volume of output $V_{h}$ obtained with one or half a rotation of the sample, and the unit energy of mining $E_{j h}$. Subscript $\mathrm{m}$ denoted variables for unassisted mining and subscript $\mathrm{h}$-variables for mining assisted by HPW jets. The volume of rock mined without HPW jet $V_{m}$ was calculated according to formula (1), while the volume of rock excavated in the mining process assisted by HPW jets, $V_{h}$, was calculated according to formula (2). In the case of hydro-mechanical mining with two values $g$ of cut slots depth, the volume of mined rock was calculated separately for each depth:

$$
\begin{gathered}
V_{m}=\pi \cdot R_{u} \cdot d_{1 m} \cdot W_{m}, \mathrm{~m}^{3} \\
V_{h}=0.5 \cdot \pi \cdot R_{u} \cdot W_{h} \cdot\left(2 \cdot d_{1 h}+h_{w}+h_{z}\right), \mathrm{m}^{3}
\end{gathered}
$$

The unit mining energy without the HPW jet assistance $E_{j m}$ was calculated with Equation (3), and the unit mining energy in the assisted mining process $E_{j h}$ was calculated with Equation (4). For hydro-mechanical mining, the energy expended on producing two high-pressure jets with a given nozzle outlet diameter $d$ and pressure $p_{0}$, which cut the slots along the entire circumference of the sample, at the set speed of nozzle movement in relation to the sample surface, was additionally calculated.

$$
\begin{gathered}
E_{j m}=\frac{2 \cdot \sqrt{P d_{m}^{2}+P s_{m}^{2}+P b_{m}^{2}}}{d_{1 m} \cdot W_{m}}, \mathrm{MJ} / \mathrm{m}^{3} \\
E_{j h}=\frac{1}{V_{h}} \cdot\left(2 \cdot \pi \cdot R_{u} \cdot \sqrt{P d_{h}{ }^{2}+P s_{h}{ }^{2}+P b_{h}{ }^{2}}+p_{o} \cdot v_{o} \cdot \frac{120000 \cdot \pi \cdot d^{2}}{4 \cdot \omega}\right), \mathrm{MJ} / \mathrm{m}^{3}
\end{gathered}
$$


where:

$v_{0}$-speed of water outflow from the nozzle, $\mathrm{m} / \mathrm{s}$, expressed by Equation (5):

$$
v_{o}=0.817\left(\frac{2 p_{0}}{\rho}\right), \mathrm{m} / \mathrm{s}
$$

where:

$\rho$-water density, $\mathrm{kg} / \mathrm{m}^{3}$.

The calculated average values of forces acting on the mining tool when mining the amount of output $V$, with the expended unit energy of mining $E_{j}$ during the process without and with HPW jet assistance, the measured values of depth $d_{1}$ and width $W$ of the obtained cut, as well as the depth of chipping on the edges of the cut $h_{w}$ and $h_{z}$ enabled a graphical interpretation of the test results and their comparison for individual measurement series. The diagram in Figure 19 compares the load on the disk tool with a cutting edge angle $2 \beta$ of $90^{\circ}$, the amount of excavated material $V$ and the unit energy of mining $E j$ for the mining process without and with HPW jets for the same mining parameters: edge penetration depth h, edge angle $2 \beta$, cutting radius $R_{u}$ and sample compressive strength $R_{c}$, with varying values of the depth of the cut slots $g$ and their spacing $2 B$.

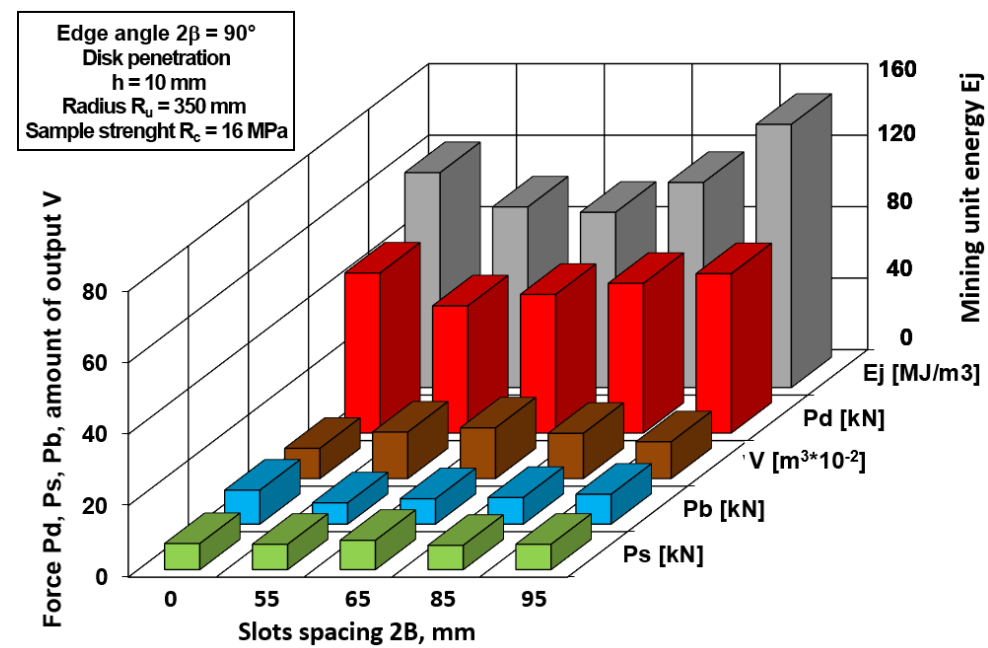

Figure 19. The value change of the pressure force $\mathrm{Pd}$, tangential force $\mathrm{Ps}$ and side force $\mathrm{Pb}$, the amount of output $\mathrm{V}$ and the mining unit energy $\mathrm{Ej}$ as a function of slots spacing $2 B$ for depth of slots $\mathrm{g}=10 \mathrm{~mm}[1]$.

For the same depth $g$ of the cut slots, with the nozzle spacing $2 B$ comparable to the cut width obtained in mechanical mining, the values of pressure force $P d_{h}$, side force $P b_{h}$ and the unit energy of mining $E_{j h}$ were reduced, and the amount of output $V_{h}$ increased. The value of tangential force $P s_{h}$ remained almost unchanged compared to $P s_{m}$. An increase of the nozzle spacing $2 B$ results in an increase of pressure force $P d_{h}$ and side force $P b_{h}$. With the spacing of nozzles $2 B>1.5 \mathrm{~W}$, the values of these forces are comparable to those for mechanical working.

The volume of output $V_{h}$ increases with the spacing of nozzles $2 B \cong 1.2 \mathrm{~W}$, and slowly decreases with a larger spacing, whereas the value of unit energy of mining $E_{j c}$ changes in the opposite way. With the spacing of nozzles $2 \mathrm{~B} \cong 1.2 \mathrm{~W}_{m}$, it is the lowest, and when the spacing increases above $1.5 \mathrm{~W}_{m}$, it is comparable or higher than the unit energy of mining for mechanical mining [1].

For several measurements, the grain size distribution of the output obtained in the mining process without and with HPW jet assistance was compared. The application of HPW jets increased the share of grain class $+25 \mathrm{~mm}$ by approximately $17 \div 26 \%$ and reduced the share of grain class $-10 \mathrm{~mm}$ by $12 \div 18 \%$. 


\section{Development of a Theoretical-Empirical Model of Hydromechanical Mining of Rocks with Disk Tools}

The obtained test results enable determining tendencies for individual values of the disk tool load, the amount of excavated material and the energy consumption of the mining process. However, they do not allow answering the question regarding the selection of the most favourable parameters of HPW jets assisting the process of mining with a disk tool so as to increase the mining efficiency or reduce the load on the tool, or the unit energy of mining. To achieve this goal, the author subjected the research results to dimensional analysis $[28,29]$. It is a mathematical tool of the theory of similarity, which facilitates obtaining the results in the form of formalised dependencies that enable creating correct physical formulas to describe phenomena in terms of quality and quantity. It also allows determining the smallest number of factors describing the analysed phenomenon and provides similarity criteria that enable a wider use of research results. The similarity criteria obtained by the dimensional analysis, based on the mapping of physical phenomena, force their experimental evaluation. The procedure for the results obtained during the test of a disk tool mining a rock sample without the assistance of HPW jets has been presented below. The procedure for the results obtained in the mining process assisted by HPW jets was the same [1].

The load on the disc tool in the process of mining without HPW jet assistance, i.e., the values of pressure force $P d_{m}$, tangential force $P s_{m}$ and side force $P b_{m}$, can be presented in the form of the following function:

$$
P d_{m}, P s_{m}, P b_{m}=F\left((P d, P s, P b), R_{u}, 2 \beta, \phi, R_{c}, h, v_{u}\right), \mathrm{N}
$$

where the left side contains dependent variables and the right side the significant and measurable independent variables.

The values of pressure force $P d$, tangential force $P s$ and side force $P b$ were estimated according to theoretical dependencies. A comparison of theoretical values calculated according to the available models with the values obtained in measurements during the conducted research revealed the best convergence (the smallest discrepancy between the theoretical and measured values) in the case of the model developed by Korzen and Lewicki [30]. This model was the only one that allowed estimating the value of all three component forces $P d, P s$ and $P b$. The relationships for calculating the theoretical value of pressure force $P d$, tangential force $P s$ and side force $P b$ are presented below:

$$
\begin{gathered}
P d=\frac{\pi}{200\left(1-v^{2}\right)} \sqrt{\frac{20 R_{r} E}{3 K^{\prime} N^{\prime}}} \sqrt{D h-h^{2}} h \operatorname{tg} \beta+\frac{h l c \operatorname{tg}\left(\beta+\rho_{z}\right) 10^{-3}}{\cos \Psi \sin \Psi-\operatorname{tg} \phi \sin ^{2} \Psi}, \mathrm{N} \\
P s=\frac{2 P d}{D}\left(\frac{4 \sqrt{D h-h^{2}}}{3 \pi}+\mu \frac{D_{o}}{2}\right), \mathrm{N} \\
P b=\frac{h l c}{1000\left(\cos \Psi \sin \Psi-\operatorname{tg} \phi \sin ^{2} \Psi\right)}, \mathrm{N}
\end{gathered}
$$

where:

$\mathrm{K}^{\prime}, \mathrm{N}^{\prime}, 1, \mathrm{c}$-coefficients and variables determined according to [27],

$\mathrm{D}_{0}$-disk tool spigot diameter, $\mathrm{mm}$,

$\mu-$ metal-to-metal friction coefficient.

The criterion numbers were determined by the matrix method for determining the system of dimensionless products [28,30]. For example, for pressure force $P d$, the matrix of variables in dependence (6), to which the new variables $p_{i}(i=0,1, \ldots, 7)$ have been assigned, will take the following form (Table 1): 
Table 1. Matrix of variables for determining the system of dimensionless products.

\begin{tabular}{ccccccccc}
\hline $\begin{array}{c}\text { Unit } \\
(\mathbf{S I})\end{array}$ & $\mathbf{P d}_{\mathbf{m}}$ & $\mathbf{P d}$ & $\mathbf{R}_{\mathbf{u}}$ & $\boldsymbol{\varphi}$ & $\mathbf{2 \beta}$ & $\mathbf{R}_{\mathbf{c}}$ & $\mathbf{h}$ & $\mathbf{v}_{\mathbf{u}}$ \\
\hline $\mathrm{m}$ & $\mathbf{p}_{\mathbf{0}}$ & $\mathbf{p}_{\mathbf{1}}$ & $\mathbf{p}_{\mathbf{2}}$ & $\mathbf{p}_{\mathbf{3}}$ & $\mathbf{p}_{\mathbf{4}}$ & $\mathbf{p}_{\mathbf{5}}$ & $\mathbf{p}_{\mathbf{6}}$ & $\mathbf{p}_{\mathbf{7}}$ \\
\hline $\mathrm{m}$ & 1 & 1 & 1 & 0 & 0 & -1 & 1 & 1 \\
\hline $\mathrm{sg}$ & 1 & 1 & 0 & 0 & 0 & 1 & 0 & 0 \\
\hline $\mathrm{rad}$ & -2 & -2 & 0 & 0 & 0 & -2 & 0 & -1 \\
\hline
\end{tabular}

After checking the assumptions of the matrix method applicability [31] and performing the necessary operations and transformations, one obtains a complete set of criterion numbers from the above matrix:

$$
\pi_{o}=\frac{P d_{m}}{R_{c} h^{2}}, \pi_{1}=\frac{P d}{R_{c} h^{2}}, \quad \pi_{2}=\frac{R_{u}}{h}, \pi_{3}=\frac{\varphi}{2 \beta}
$$

by introducing:

$$
\pi_{o 1}=\frac{\pi_{0}}{\pi_{1}}=\frac{P d_{m}}{P d}
$$

Equation (6) can be presented in the following form:

$$
P d_{m}=P d \Phi \cdot\left(\frac{R_{u}}{h}, \frac{\phi}{2 \beta}\right)
$$

The form of the function $\Phi$ can only be determined experimentally. The same form will be taken by the relations for the tangential force $P s$ and the side force $P b$. Thus, in the load tests of a symmetric disk tool, the similarity criteria will have the following form:

$$
\frac{R_{u}}{h}=\frac{R_{u}^{\prime}}{h^{\prime}} \text { and } \frac{\varphi}{2 \beta}=\frac{\varphi^{\prime}}{2 \beta^{\prime}}
$$

The processing of the remaining results was similar. The Equations (14)-(17) present the function forms for the remaining dependent variables- the values of pressure force $P d_{h}$, tangential force $P s_{h}$ and side force $P b_{h}$ in the assisted mining process, depth $g$ of the cut slot, bottom depths $d_{1 m}$ and $d_{1 h}$ and the cut's width $W_{m}$, as well as the chipping depths on the cut borders $h_{w}$ and $h_{z}$ :

$$
\begin{gathered}
P d_{h}, P s_{h}, P b_{h}=F\left((P d, P s, P b), R_{u}, 2 \beta, \phi, R_{c}, h, v_{u}, g, 2 B\right), \mathrm{N} \\
g=F\left(l, p, v_{0}, v_{p}, R_{c}, d\right), \mathrm{mm} \\
d_{1 m}, d_{1 h}, W_{m}=F\left(\left(d_{1}, W\right), R_{u}, D, 2 \beta, \phi, R_{c}, h, v_{u}\right), \mathrm{mm} \\
d_{1 m}, d_{1 h}, W_{m}=F\left(\left(d_{1}, W\right), R_{u}, D, 2 \beta, \phi, R_{c}, h, v_{u}\right), \mathrm{mm}
\end{gathered}
$$

The form of function $\Phi$, separately for each analysed value, based on physical formulas and measurement data obtained according to dependence (12), was developed on the basis of multiple regression analysis [32], using the program implementing the step regression procedure included in the Statistica package. When testing the significance of the members of the regression function, the Student's t-test was used to estimate the significance of a given member. The adopted level of significance $\alpha=0.10$ is recommended for this method. The procedures of the Statistica package at each stage of model development enabled calculating the value of multivariate correlation coefficient $R$ and the percentage of explained variation $\mathrm{R}^{2}$. The model with the highest multivariate correlation coefficient $R$, the highest percentage of explained variance $R^{2}$ and the highest number of significant members with independent variables was assumed as the most favourable [31]. An 
example of one of the models obtained for the pressure force during mining without HPW jets $\mathrm{Pd}_{\mathrm{m}}$ is shown in Table 2.

Table 2. Form of the model of the pressure force during mining without high-pressure assistance Pdm, together with the values of the estimated parameters [1].

\begin{tabular}{cccc}
\hline Model form & \multicolumn{2}{c}{$P d_{m}=P d \cdot\left[\exp \left(a_{1} \frac{R_{u}}{h}\right)+a_{2} \cdot \ln \left(\frac{\phi}{2 \beta}\right)+a_{3}\right]$} \\
\hline Parameter evaluation & -0.00189 & $\boldsymbol{a}_{\mathbf{2}}$ & $\boldsymbol{a}_{\mathbf{3}}$ \\
\hline Standard error & 0.00055 & 0.27807 & 0.26861 \\
\hline Student's -test value & -3.46031 & 0.05892 & 0.08572 \\
\hline Significance level p & 0.00132 & 4.71958 & 3.19237 \\
\hline \multicolumn{2}{c}{0.00017} \\
\hline \multicolumn{3}{c}{$\mathrm{R}=0.959$} \\
\hline \multicolumn{3}{c}{$\mathrm{R}^{2}=91.75 \%$} \\
\hline \multicolumn{2}{c}{ Percentage of explained variance }
\end{tabular}

Based on the obtained models, analytical and empirical formulas were developed to calculate the load on the symmetrical disc tool (values of pressure force $P d$, tangential force $P s$ and side force $P b$ ) and the efficiency of rock mining (depth of cut slots $g$, the obtained cut's depth $d_{1}$ and width $W$, chipping depth on the borders of the cut $h_{w}$ and $h_{z}$ ) during mining without and with the assistance of HPW jets. These formulas have been presented below:

$$
\begin{gathered}
P d_{m}=P d \cdot\left[\exp \left(-0.00189 \frac{R_{u}}{h}\right)+0.27807 \cdot \ln \left(\frac{\phi}{2 \beta}\right)+0.26961\right] \\
P d_{h}=P d \cdot\left[\left(\frac{g}{h}\right)^{-0.185}-\left(\frac{R_{u}}{h}\right)^{0.056}+0.527 \cdot \ln \left(\frac{\phi}{2 \beta}\right)+0.314 \cdot \ln \left(\frac{2 B}{W_{m}}\right)+1.56\right] \\
P s_{m}=P s \cdot\left[\frac{0.02847}{1-0.92574 \exp \left(-0.00047 \frac{R_{u}}{h}\right)}+\left(\frac{\phi}{2 \beta}\right)^{0.18404}\right] \\
P s_{h}=P s \cdot\left[-0.1299 \cdot\left(\frac{g}{h}\right)-0.0051 \cdot\left(\frac{R_{u}}{h}\right)+0.2827 \cdot \ln \left(\frac{2 B}{W_{m}}\right)+1.2942\right] \\
P b_{h}=P b \cdot\left[-1.26 \cdot\left(\frac{g}{h}\right)-0.07 \cdot\left(\frac{R_{u}}{h}\right)-1.53 \cdot \ln \left(\frac{\phi}{2 \beta}\right)+1.69 \cdot \ln \left(\frac{2 B}{W_{m}}\right)+4.2\right] \\
g=d \cdot\left[3.4508\left(\frac{p}{R_{c}}\right)^{1.09715}-0.01771\left(\frac{L}{d}\right)+2.5996 \ln \left(\frac{v_{0}}{v_{p}}\right)-11.722\right] \\
d_{1 m}=d_{1} \cdot\left[\exp \left(0.00151 \cdot \frac{R_{u}}{h}\right)+0.49862 \cdot \ln \left(\frac{\phi}{2 \beta}\right)+0.41817\right] \\
W_{z}=h \cdot\left[2518.6 \cdot\left(\frac{R_{u}}{g}\right)^{-3.090}-0.685 \cdot \ln \left(\frac{\phi}{2 B}\right)-0.599 \cdot\left(\frac{2 B}{W_{m}}\right)^{1.9374}-0.3104\right] \\
h_{w}=h \cdot\left[\exp \left(-0.00265 \cdot \frac{R_{u}}{h}\right)+0.08538\right] \\
\left.29.02 \cdot\left(\frac{R_{u}}{g}\right)^{-1.3531}-0.638 \cdot \ln \left(\frac{\phi}{2 B}\right)-0.2936 \cdot\left(\frac{2 B}{W_{m}}\right)^{2.4564}-0.064\right] \\
{\left[\begin{array}{l}
2 \beta \\
h
\end{array}\right]}
\end{gathered}
$$


The obtained formulas enabled writing a computer program for calculating the load on the symmetrical disk tool and the mining effect when mining the rock without or with the assistance of HPW jets. The structure of the program allowed calculating the values of pressure force $P d$, tangential force $P s$ and side force $P b$, the volume of excavated rock $V$ and the unit energy of mining $E j$ for the given mining parameters, as well as comparing the load on the tool, the volume of the excavated rock and the unit energy of assisted and unassisted mining. In the case of assisted mining with the preset mechanical mining parameters, the program also enabled determining the values of cut slots' depth $g$ and their spacing $2 B$ for which the load on the disk tool was the lowest, the unit energy of mining was the lowest and the amount of excavated material was the largest [1].

The obtained results allowed determining the effects of the application of HPW jets and specifying the most favourable operating parameters for the symmetrical disk toolthe HPW jets system. The most representative results have been presented in the form of graphs in Figures 20 and 21.

a)

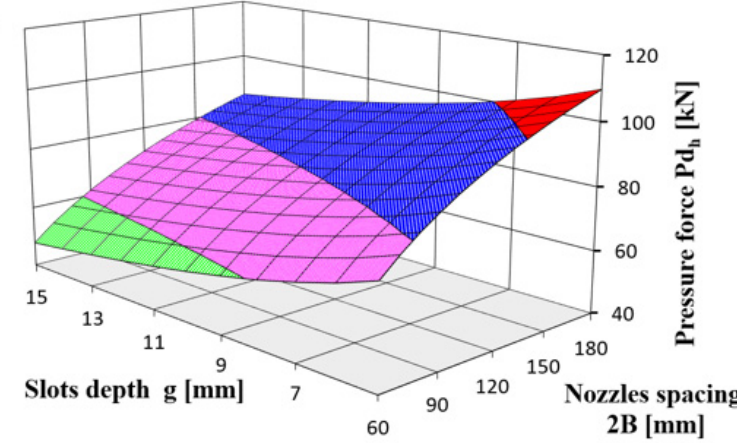

b)

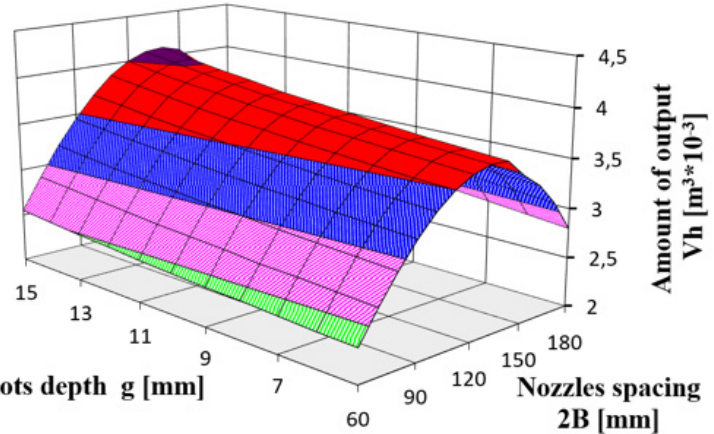

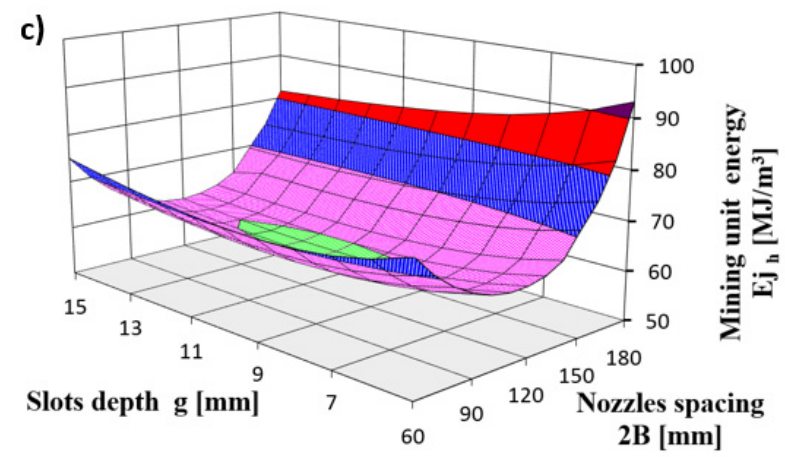

Figure 20. The value of the pressure force Pd (a), the amount of output $V(\mathbf{b})$ and the mining unit energy $\mathrm{Ej}(\mathbf{c})$ for mining with the disk tool with HPW jets assistance as a function of slots spacing $2 \mathrm{~B}$ and depth of slots g; disk edge angle $2 \beta=130^{\circ}$; disk edge penetration depth $h=10 \mathrm{~mm}$; mining radius $R_{u}=350 \mathrm{~mm}$; sample compressive strength $R_{c}=14.5 \mathrm{MPa}$ [1].

According to the graphs presented in Figure 20, for the given mechanical parameters of mining (edge penetration depth $h$, cutting edge angle $2 \beta$, cutting radius $R_{u}$ and type of rock sample), the most favourable operating parameters of the disk tool-the high-pressure nozzles system - can be determined in terms of: disk tool load, energy consumption and efficiency of the mining process for the given mining parameters. The graph shows only the value of pressure force $P d$, which, however, has a decisive influence on the total load on the disk tool [1].

The second type of graphs, presented in Figure 21, enables determining the effects of applying HPW jets as compared to mechanical mining, with different parameters of the water jet assisting the mining process. The results shown in Figures 20 and 21 were discussed in more detail in the next chapter. On their basis, the most favourable operating parameters for hydromechanical mining of rocks with disc tools were proposed. 


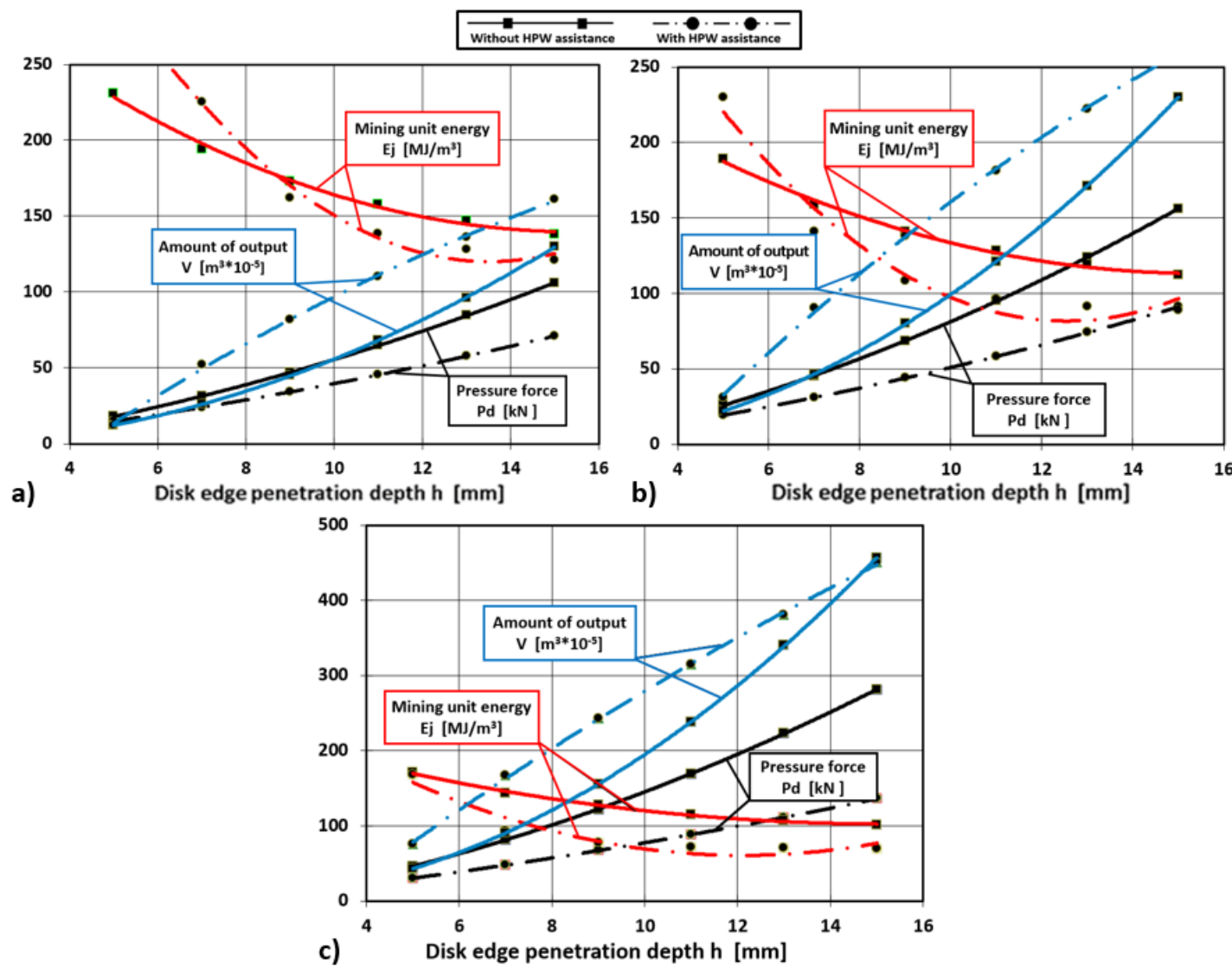

Figure 21. The value change of the pressure force $\mathrm{Pd}$, the amount of output $\mathrm{V}$ and the mining unit energy Ej for mining with disk tool without and with HPW jets assistance, for the same mining parameters, as a function of disk edge penetration depth h: (a) disk edge angle $2 \beta=90^{\circ}$, nozzle spacing $2 \mathrm{~B}=50 \mathrm{~mm}$, (b) disk edge angle $2 \beta=110^{\circ}$, nozzle spacing $2 \mathrm{~B}=70 \mathrm{~mm}$, (c) disk edge angle $2 \beta=130^{\circ}$, nozzle spacing $2 \mathrm{~B}=100 \mathrm{~mm}[1]$.

\section{Discussion and Conclusions}

The analysis of the conducted research results has demonstrated that the influence on the load variability (the values of pressure force $\mathrm{Pd}$, tangential force $\mathrm{Ps}$ and side force $\mathrm{Pb}$ ), as well as the effect and energy consumption of the process of mining along the circular trajectory of the rock mass with the symmetrical disk tool, have mainly edge penetration depth $h$, disk tool edge angle $2 b$, physical and mechanical properties of the excavated rock sample, mining radius $R_{u}$, and, additionally, the spacing of slots $2 B$ and their depth $g$ in the case of mining assisted by high-pressure water jets $[1,6,7,21,24]$.

The most advantageous location of high-pressure jets is their symmetrical arrangement on the sides of the disk tool. Applying an additional water jet along the axis of the disk tool increases the assistance effect (by approximately $50 \%$ in terms of a reduction of load on the tool, increase of the mining efficiency and output grain fraction $+25 \mathrm{~mm}$ ), but at the same time, it almost doubles the demand for energy needed to generate the jets and the amount of water in the face $[1,11,12]$.

The application of two high-pressure water jets to assist the process of mining the rock mass with the symmetrical disk tool, depending on the size of slots spacing $2 \mathrm{~B}$, their depth $\mathrm{g}$ and edge angle $2 \beta$, for the same mining parameters, compared to mechanical mining [1] causes a decrease in the value of pressure force Pd by nearly $50 \%$, in the value of side force $\mathrm{Pb}$ by $35 \%$ and an increase in the amount of output $\mathrm{V}$ by $105 \%$, with the unit energy of mining Ejh comparable or higher by $45 \%$ than Ejm. The value of tangential force Ps did not change much. The decrease in the value of pressure force $\mathrm{Pd}$ and side force $\mathrm{Pb}$ is more significant for larger edge angles $2 \beta$, while the increase in the amount of output Vh is greater for smaller edge angles $2 \beta[1,5-7,11,21]$. 
The depth of slots cut with HPW jets $g$, which is lower than the disk tool edge penetration depth $h$, does not allow obtaining satisfactory results, even when the slots spacing $2 B$ is six times smaller than depth $h[1,21,24]$.

The analytical and empirical model of the load on the symmetrical disk tool and the effects of mining along the rock mass circle without and with the assistance of HPW jets, which has been developed on the basis of the conducted research results, makes it possible to accurately determine the impact of this assistance on the mining process and to select the most favourable operating parameters for the single symmetrical disk tool—-the HPW jet system in the studied area [1].

To obtain a rectangular section of the cut's surface, the author recommended using the spacing of nozzles $2 \mathrm{~B} \leq \mathrm{Wm}$-the theoretical width of the cut-while the depth of the slots should be greater than $1.75 \mathrm{~d}_{1}$ - the depth of the obtained cut. This will enable reducing the value of pressure force $\mathrm{Pd}$ to $50 \%$ and increase the amount of output $\mathrm{V}$ to $175 \%$, with the unit energy of mining Ej being increased by $45 \%$ compared to mining without the assistance [1].

The author stated, based on the calculated results using the developed program, that the most advantageous parameters for HPW jets to assist the mining of rock mass with symmetrical disk tools, i.e., the spacing of nozzles $2 \mathrm{~B}$ and the depth of slots $\mathrm{g}$, with the greatest reduction in the value of pressure force $\mathrm{Pd}$, the greatest increase in the amount of output $\mathrm{V}$ and the minimum value of unit mining energy $\mathrm{Ej}$, as compared to mechanical mining, are within the following limits [1]:

$$
\begin{gathered}
W_{m} \leq 2 B \leq 1.3 W_{m}, \mathrm{~mm} \\
h \leq \mathrm{g} \leq 1.5 h, \mathrm{~mm}
\end{gathered}
$$

After taking into account the similarity criteria for the mined rock sample (mechanical properties - especially uniaxial compression strength $R_{c}$ and internal friction angle $\phi$ ), with the use of the model developed by the author, it is possible to estimate the most advantageous working parameters while hydromechanical mining on a larger cutting radius, using symmetrical disks [1].

Author Contributions: Conceptualisation, supervision, methodology, validation, formal analysis, investigation, resources, data curation and visualisation, software, writing - original draft preparation and project administration, writing-review and editing, funding acquisition, K.K. The author has read and agreed to the published version of the manuscript.

Funding: The article uses the results of the author's own research. The part of the research related to the development of the theoretical-empirical model, as part of Research Project No. 10.130.858, was co-financed by the funds of the Polish Scientific Research Committee.

Institutional Review Board Statement: Not applicable.

Informed Consent Statement: Not applicable.

Data Availability Statement: Not applicable.

Conflicts of Interest: The author declares no conflict of interest.

\section{References}

1. Kotwica, K. Application of Water Assistance in the Process of Mining Rock with Mining Tools; Monographs No 260; AGH University of Science and Technology: Kraków, Poland, 2012. (In Polish)

2. Liu, S.Y.; Liu, Z.H.; Cui, X.X.; Jiang, H. Rock breaking of conical cutter with assistance of front and rear water jet. Tunn. Undergr. Space Technol. 2014, 42, 78-86. [CrossRef]

3. Timko, R.J.; Johnson, B.; Thimons, E.D. Water-Jet-Assisted Roadheadrs; Information Circular IC-9108; US Bureau of Mines: Washington, DC, USA, 1986.

4. Nienhaus, K.; Weiglt, H.; Thimons, E.D. The development of a water-jet-assisted shearer loader. In Proceedings of the 8th International Symposium on Jet Cutting Technology, Durham, UK, 9-11 September 1986; pp. 79-92. 
5. Baumann, L.; Henneke, J. Untersuchungen zur Verringerung des Energieaufwands in Tunnelbohrmaschinen mit Diskenrollenbohrwerkzeugen und Hochdruckwasserstrahlen. Glückauf-Forsch. 1980, 41, 238-241.

6. Baumann, L.; Henneke, J. Verringern der Vorschubkraft Und Erhoehen der Vortriebsgeschwindigkeit von Tunnelbohrmaschinen mit Hilfe von Hochdruckwasserstrahlen. Glückauf-Forsch. 1980, 41, 193-196.

7. Baumann, L. Versuche mit Hochdruckwasserstrahlen an einer Tunnelbohrmaschine. Glückauf 1980, 116, $1113-1117$.

8. Baumann, L.; Henneke, J. Attempt of Technical-Economical Optimization of High-Pressure Jet Assistance for Tunneling Machines. In Proceedings of the 5th International Symposium on Jet Cutting Technology, Hannover, Germany, 2-4 June 1980; pp. 119-136.

9. Hood, M.; Knight, G.C.; Thimons, E.D. A Review of Water-Jet-Assisted Rock Cutting; Information Circular; US Bureau of Mines: Washington, DC, USA, 1990.

10. Kleinert, H.W. Hydroschneiden mit Schneidköpfen von Teilschnitt Vortriebsmaschinen. Glückauf Forsch. 1985, 46, $223-227$.

11. Kuzmich, I.A.; Routberg, M.S.; Mierzliakow, V.G. Investigation Results for Schemes of Rock Brekage with High-Speed Water and Shearing Disc; Skochinsky Institute of Mining: Moscow, Russia, 1980; Volume 140, pp. 136-154.

12. Kuzmich, I.A. Coal-cutting technology with water jest in the USSR. In Proceedings of the 5th International Symposium on Jet Cutting Technology, Hanover, Germany, 2-4 June 1980.

13. Vaśek, J. Theoretical evaluation of pick tips assisted by high pressure water jets. In Proceedings of the 11th International Conference "Jet Cutting Technology", St. Andrews, Scotland, 8-10 September 1992.

14. Xiaohui, L.; Songyong, L.; Lie, L.; Xinxia, C. Experiment on Conical Pick Cutting Rock Material Assisted with Front and Rear Water Jet. Adv. Mater. Sci. Eng. 2015, 2015, 506579.

15. Vaśek, J.; Pinka, J. High energy liquid jet assistance of rock cutting process. Trans. Fac. Min. Geol. 1995, 34, 95-104.

16. Ciccu, R.; Grosso, B. Improvement of the excavation performance of PCD drag tools by water jet assistance. Rock Mech. Rock Eng. 2010, 43, 465-474. [CrossRef]

17. Henneke, J.; Baumann, L. Technische Verbesserungen des maschinellem Gesteinsstreckenvortriebes. Glückauf 1979, 5, 32-38.

18. Stoxreitera, T.; Martinb, A.; Tezac, D.; Gallera, R. Hard rock cutting with high pressure jets in various ambient pressure regimes. Int. J. Rock Mech. Min. Sci. 2018, 108, 179-188. [CrossRef]

19. Ciccu, R.; Grosso, B. Improvement of disc cutter performance by water jet assistance. Rock Mech. Rock Eng. 2014, 47, 733-744. [CrossRef]

20. Wang, F.D.; Ozdemir, L.; Snydler, L. Prediction and Verification of Tunnel Boring Machine Performance; Access Conferences Ltd.: Beaconsfield, UK, 1978; pp. 123-132.

21. Jinliang, Z.; Yongchang, L.; Yuansheng, Z.; Fengwei, Y.; Chao, L.; Shunhui, T. Using a HPW jet-assisted tunnel boring machine to break rock. Adv. Mech. Eng. 2020, 12, 1-16.

22. Brochure of Robbins Company. Available online: https://www.robbinstbm.com/news-and-media/brochures-spec-sheets/ (accessed on 12 June 2009).

23. Brochure of Wirth Company. WIRTH Hard Rock Tunneling; The Breakthrough: Erkelenz, Germany, 1997.

24. Fengchao, W.; Dapeng, Z.; Xin, Z.; Nanzhe, X.; Chuwen, G. Rock Breaking Performance of TBM Disc Cutter Assisted by HPW Jet. Appl. Sci. 2020, 10, 1-12.

25. Kotwica, K.; Stopka, G.; Prostański, D. Study and Application of Asymmetrical Disk Tools for Hard Rock Mining. Energies 2021, 14, 1826. [CrossRef]

26. Dutta, P.K. A Theory of Percussive Drill Penetration. Int. J. Rock Mech. Sci. 1972, 9, 543-567. [CrossRef]

27. Marianowski, J. Badania Laboratoryjne i Analiza Teoretyczna Procesu Wnikania Ostrzy Koronek w Skały Przy Wierceniu Udarowym i Obrotowo-Udarowym. Ph.D. Thesis, AGH University of Science and Technology, Kraków, Poland, 1980. (In Polish).

28. Drobot, S. O analizie wymiarowej. Zastos. Mat. 1954, 1, 7-134. (In Polish) [CrossRef]

29. Furmanik, K. Zagadnienia podobieństwa mechanicznego w badaniach przyczepności koła do szyny. Zagadnienia Eksploat. Masz. 1980, 2, 181-189. (In Polish)

30. Korzeń, Z.; Lewicki, M. Obciążenia zewnętrzne narzędzi dyskowych w procesie urabiania skał twardych. Arch. Min. Sci. 1990, 35, 279-304. (In Polish)

31. Nowak, Z. Ogólna teoria wyznaczania zupełnego układu iloczynów bezwymiarowych. Czas. Tech. 1969, 6, 34-47. (In Polish)

32. Mańczak, K. Technika Planowania Eksperymentu; WNT: Warszawa, Poland, 1976. (In Polish) 